\title{
Evaluating Iodine Uptake in a Crystalline Sponge using Dynamic X-ray Crystallography
}

William J. Gee,$^{\dagger \dagger}$ Lauren E. Hatcher,${ }^{\dagger}$ Christopher A. Cameron, ${ }^{\dagger \S}$ Clare Stubbs,${ }^{\dagger}$ Mark R. Warren, Andrew D. Burrows ${ }^{* \dagger}$ and Paul R. Raithby*广§

$\dagger$ Department of Chemistry, University of Bath, Claverton Down, Bath, BA2 7AY, UK.

$\ddagger$ School of Physical Sciences, University of Kent, Canterbury, Kent, CT2 7NH, UK.

$\S$ Research Complex at Harwell, Rutherford Appleton Laboratory, Didcot, Oxfordshire, OX11 OFA, UK.

I Diamond Light Source, Diamond House, Harwell Science and Innovation Campus, Didcot, Oxfordshire, OX11 0DE, UK.

KEYWORDS: Metal-organic framework, crystalline sponge, iodine, time-resolved crystallography, crystalline molecular flask

ABSTRACT: The uptake of gaseous iodine into the crystalline sponge material $\left[\left(\mathrm{ZnI}_{2}\right)_{3}(\mathrm{tpt})_{2}\right] \cdot 0.7$ triphenylene $\cdot 0.3 \mathrm{PhNO}_{2} \cdot 0.7 \mathrm{C}_{6} \mathrm{H}_{12} \mathbf{1}(\mathrm{tpt}=2,4,6$-tris(4-pyridyl)-1,3,5-triazine $)$ has 
been monitored by dynamic X-ray diffraction and thermogravimetric analysis. The X-ray analyses have enabled the location, quantity, uptake rate and subsequent chemistry of the iodine upon inclusion into the pores to be determined. An uptake of $6.0 \mathrm{wt} \%\left(0.43 \mathrm{I}_{2}\right.$ per formula unit) was observed crystallographically over a period of 90 minutes before crystal degradation occurred. The included iodine molecules interact with the iodine atoms of the $\mathrm{ZnI}_{2}$ nodes at three different sites, forming coordinated $\mathrm{I}_{3}{ }^{-}$ions. The results contrast to recent observations on $\left[\left(\mathrm{ZnI}_{2}\right)_{3}(\mathrm{tpt})_{2}\right]$ without the triphenylene guests which show the presence of $\mathrm{I}_{4}{ }^{2-}$ ions with low quantities of absorbed iodine.

\section{INTRODUCTION}

The capture and immobilization of radioactive iodine ${ }^{1}$ is highly topical given the unplanned release of radioactive material from the Fukushima nuclear power plant in $2011 .^{2}$ Concern surrounding the beta-emitting isotopes ${ }^{129} \mathrm{I}$ and ${ }^{131} \mathrm{I}$ stems largely from the volatility of iodine, coupled with its ability to impact upon human metabolic processes. ${ }^{3}$

Metal-organic frameworks (MOFs) are a promising class of materials for the sequestration of iodine, including its radioactive isotopes, owing to their high porosity, tunable pore dimensions, and affinity for a wide range of guests. ${ }^{4-6}$ This has been borne out in a number of MOF systems, including MIL-type aluminum scaffolds, ${ }^{7}$ zinc paddlewheels, ${ }^{8}$ zirconium UiO-66 derivatives ${ }^{9}$ and zeolitic imidazolate frameworks. ${ }^{10}$ These studies, combined with in silico insights, ${ }^{11}$ have identified iodine as having an affinity for metal sites and nucleophilic functional groups. Composite materials containing MOFs have been proposed for the sequestration of iodine, ${ }^{12}$ as have related materials such as covalent organic frameworks ${ }^{13}$ and other porous organic frameworks. ${ }^{14}$ Interest in iodine inclusion is not limited to its radioactive isotopes, and adsorption 
of iodine can also be used to partially oxidize framework materials, and hence introduce electronic conduction..$^{15-16}$

Crystalline sponges are a subset of MOFs that have been tailored to enhance crystallographic investigations by providing a cavity capable of ordering guest molecules. ${ }^{17}$ This ordering is driven by the inherent flexibility of the framework, and crystalline sponges have been shown to be effective hosts for reactive intermediates ${ }^{18}$ and difficult to crystallize organic molecules, ${ }^{19}$ allowing structural characterization of molecules that are not amenable to traditional crystallographic techniques. When reaction intermediates and/or products are structurally characterized within the pores, the materials are often referred to as crystalline molecular flasks (CMFs) ${ }^{20-21}$

The most well-known crystalline sponges are formed from the linking together of $\mathrm{ZnI}_{2}$ nodes with 2,4,6-tris(4-pyridyl)-1,3,5-triazine (tpt) ligands. The compound $\left[\left(\mathrm{ZnI}_{2}\right)_{3}(\mathrm{tpt})_{2}\right]$, assembled from the reaction of $\mathrm{ZnI}_{2}$ with tpt, forms a doubly interpenetrated (10,3)-b network containing onedimensional channels. ${ }^{22}$ However, when the reaction between $\mathrm{ZnI}_{2}$ and tpt takes place in the presence of triphenylene a different network is formed. The included triphenylene molecules interact through $\pi \cdots \pi$ interactions with the tpt linkers forming columns, and the resultant network, $\left[\left(\mathrm{ZnI}_{2}\right)_{3}(\mathrm{tpt})_{2}\right] \cdot$ triphenylene, contains two types of channels. ${ }^{23}$ Networks based on $\mathrm{ZnI}_{2}$ nodes and tpt linkers have previously shown an affinity for iodine inclusion, resulting in either chemical reaction $^{24}$ or structural changes. ${ }^{25}$

In light of the dynamic nature of crystalline sponges in the presence of gaseous iodine ${ }^{24-25}$ and the importance of understanding iodine uptake, ${ }^{1}$ the $\left[\left(\mathrm{ZnI}_{2}\right)_{3}(\mathrm{tpt})_{2}\right]$-triphenylene system ${ }^{23}$ was targeted for investigation by dynamic X-ray crystallography. Our objective was to establish (i) the kinetics of iodine uptake, (ii) the loading of iodine inside the framework and (iii) the nature of the interaction between the iodine guest molecules, the triphenylene and host framework. The results 
of these investigations are reported herein. While this work was being carried out, Woo, Murugesu and co-workers ${ }^{26}$ reported the uptake of iodine into $\left[\left(\mathrm{ZnI}_{2}\right)_{3}(\mathrm{tpt})_{2}\right]$, so we also compare our findings in the related triphenylene-containing framework to their results.

\section{RESULTS AND DISCUSSION}

Crystals of triphenylene-loaded $\left[\left(\mathrm{ZnI}_{2}\right)_{3}(\mathrm{tpt})_{2}\right]$ were prepared following the previously reported procedure $^{27}$ and were suspended in cyclohexane to facilitate solvent exchange. The crystal structure at $290 \mathrm{~K}$ demonstrated the presence of both nitrobenzene and cyclohexane solvent molecules in the lattice and the refinement suggested the occupancy of triphenylene was $70 \%$ (vide infra), giving a formula for $\mathbf{1}$ of $\left[\left(\mathrm{ZnI}_{2}\right)_{3}(\mathrm{tpt})_{2}\right] \cdot 0.7$ triphenylene $\cdot 0.3 \mathrm{PhNO}_{2} \cdot 0.7 \mathrm{C}_{6} \mathrm{H}_{12}$. A preliminary test for uptake of gaseous iodine vapor was carried out by monitoring single crystals of $\mathbf{1}$ in the presence of solid iodine with optical microscopy. The initially yellow single crystals darkened to brown over a 10-minute period, with the color change migrating from the crystal edges inwards (Figure S3). A sample of 1 was then placed under an atmosphere of iodine vapor for two days. The color of the powder changed from yellow to black during this time, and thermogravimetric analysis (TGA) revealed a mass loss of $38.4 \%$ when the sample was heated to $200{ }^{\circ} \mathrm{C}$, equivalent to 3.9 molecules of $\mathrm{I}_{2}$ per formula unit, assuming the same composition as observed in the crystal structure prior to $\mathrm{I}_{2}$ exposure (vide infra) and also loss of the included nitrobenzene and cyclohexane concurrent with $\mathrm{I}_{2}$. This was gauged to be the maximum uptake for this system (Table S2, Figure S4).

Having demonstrated that $\mathbf{1}$ was capable of iodine uptake over a period of hours, we sought to visualize this process using dynamic single-crystal X-ray crystallography. Given the dispersive nature of released vapors, understanding the behavior of the framework towards volatile iodine 
over short timescales is crucial for gas absorption applications. These experiments were carried out on the single crystal beamline facility, I19, at the Diamond Light Source. A single crystal of $\mathbf{1}$ was mounted in a $1 \mathrm{~mm}$ glass capillary, in a static gas cell ${ }^{28}$ together with several iodine crystals, with 1 and the iodine being separated by a cotton wool plug (Figure S1). The temperature of the capillary was maintained at $290 \mathrm{~K}$, with a stream of gaseous nitrogen, and the iodine allowed to diffuse within the closed capillary. X-ray data sets, each taking approximately 20 min to record, were measured sequentially from the point at which the gas cell was mounted on the diffractometer. In total, six data sets were measured with a total X-ray exposure time of $96 \mathrm{~min}$. Over this period, the unit cell volume increased by $3.9 \%$, from $18204(1)$ to $18922(5) \AA^{3}$. For each data set the structure was refined using the structural model obtained from the $290 \mathrm{~K}$ data obtained before the absorption of iodine into the crystal (Figure 1).

\section{(a)}
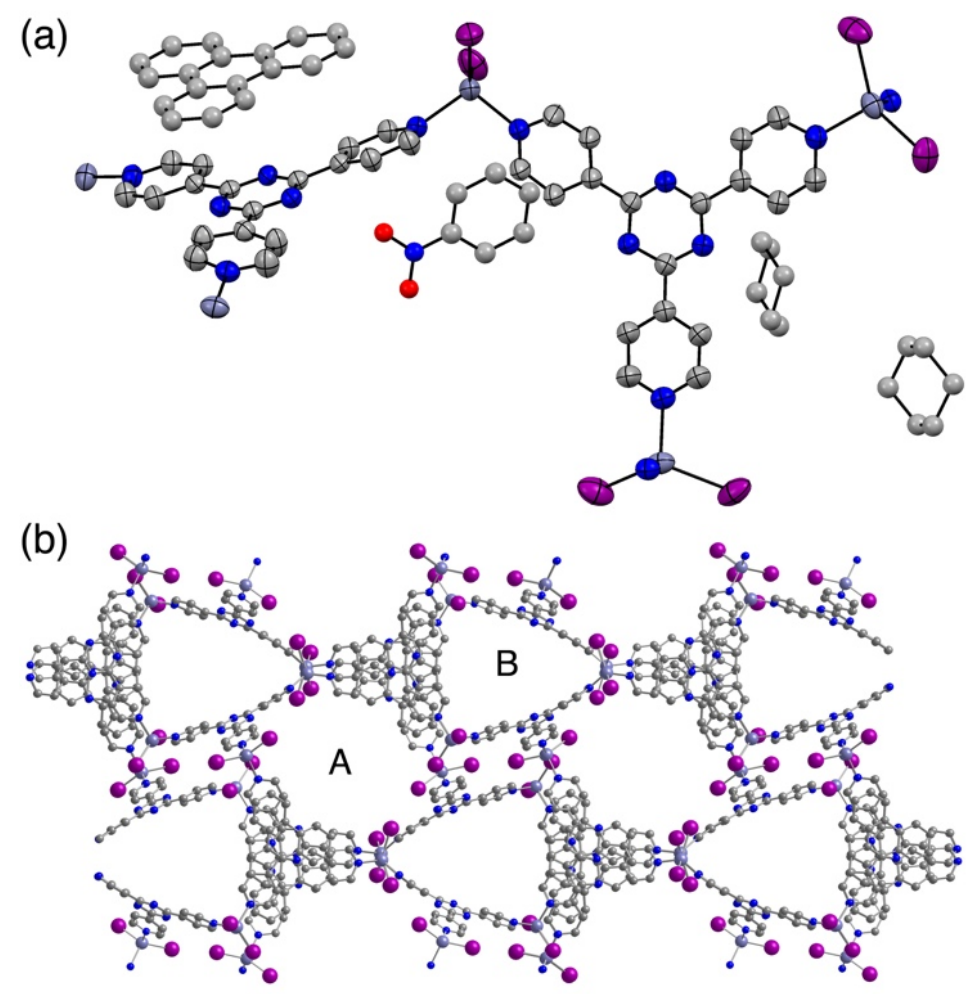
Figure 1. The structure of 1 showing (a) the asymmetric unit, indicating the positions of the triphenylene molecule and the included nitrobenzene and cyclohexane solvent molecules, and (b) the network structure showing the A and B channels, with nitrobenzene and cyclohexane molecules removed for clarity. Hydrogen atoms have been omitted for clarity.

In all data sets, the atoms of the framework and the triphenylene molecule were refined anisotropically. Refinement of the initial dataset suggested that triphenylene was present with only $70 \%$ occupancy, and in this and all subsequent datasets the occupancy was fixed at this level. There is precedence in other structural analyses of $\left[\left(\mathrm{ZnI}_{2}\right)_{3}(\mathrm{tpt})_{2}\right]$-triphenylene compounds for triphenylene occupancy of less than $100 \% .{ }^{27}$ To facilitate comparison throughout the series, the same set of constraints and restraints were applied to the solvent atoms; these were subject to an isotropic refinement, with site occupancies fixed to a constant value and isotropic displacement parameters allowed to refine freely. From the X-ray structural analysis, it was clear that iodine was being absorbed into the crystal lattice from the initial measurements, and the percentage absorption increased with time until 96 min, at which point the quality of the diffraction data was such that it could no longer be relied upon. An analysis of the electron density within the crystal lattice using PLATON SQUEEZE ${ }^{29}$ showed an increase in residual electron density with time, as presented in Table 1. In this approach the structure for the $\left[\left(\mathrm{ZnI}_{2}\right)_{3}(\mathrm{tpt})_{2}\right]$-triphenylene unit, without solvent, was used as the model structure and the residual electron density for each of the six data sets was calculated against this model, accounting for the presence of the included nitrobenzene and cyclohexane solvent molecules and the increasing percentage of iodine. 
Table 1. The increasing residual electron density with time accounting for solvent molecules and iodine as $\mathrm{I}_{2}$ is absorbed into the crystal of $\mathbf{1}$ at $290 \mathrm{~K}$.

\begin{tabular}{llll}
\hline Dataset & Time (mins) & Solvent accessible volume $\left(\AA^{3}\right)^{[\mathrm{a}]}$ & No. residual electrons \\
\hline 1 & 0 & 8198 & 1878 \\
2 & 20 & 8179 & 2096 \\
3 & 36 & 8362 & 2382 \\
4 & 50 & 8452 & 2516 \\
5 & 65 & 8547 & 2603 \\
6 & 81 & 8787 & 2682 \\
\hline
\end{tabular}

[a] The solvent accessible volume was calculated using the SQUEEZE algorithm, implemented in PLATON. ${ }^{29}$

[b] The number of residual electrons was calculated using SQUEEZE, the calculations were performed on a model containing only the host cage framework and the triphenylene guest. The number of residual electrons calculated by SQUEEZE is a measure of all the $\mathrm{PhNO}_{2}$, cyclohexane and iodine present in the lattice at the six time points, though only the electron density corresponding to $0.3 \mathrm{PhNO}_{2}, 0.7 \mathrm{C}_{6} \mathrm{H}_{12}$ and the increasing amount of coordinated $\mathrm{I}_{2}$ is modelled in the six structural analyses. There is additional poorly resolved solvent present in the crystals that cannot be modelled other than by SQUEEZE. The key point to note is that the solvent accessible volume and the residual electron density are increasing with time as iodine is absorbed by the crystal.

Carrying out sequential crystal structure determinations during $\mathrm{I}_{2}$ uptake enabled the rate of inclusion and location of the incoming iodine molecules to be determined. The structure of $\mathbf{1}$ with the absorbed $I_{2}$ after 90 min (dataset 6) is shown in Figure 2. $I_{2}$ occupies three different sites within the lattice but, in all cases, it links to an iodine atom of one of the " $\mathrm{ZnI}_{2}$ " nodes to form coordinated, linear $\mathrm{I}_{3}{ }^{-}$ligands. There are three sites of $\mathrm{I}_{2}$ occupation: in the final dataset, I_occ1 has $16 \%$ occupancy and forms a $\mathrm{I}_{3}^{-}$ligand with the Zn-coordinated atom I(5) (I(5)-I(7) 3.055(9), I(7)-I(8) 2.834(12) ̊̊), I_occ2 has a 7\% occupancy and forms a $\mathrm{I}_{3}^{-}$ligand with $\mathrm{I}(1)(\mathrm{I}(1)-\mathrm{I}(9) 3.018(10)$, 
I(9)-I(10) 2.815(19) $\AA$ ), and I_occ3 has 20\% occupancy and forms a $\mathrm{I}_{3}{ }^{-}$ligand with I(2) (I(2)$\mathrm{I}(11) 3.324(11)$, I(11)-I(12) 2.814(14) $\AA$ ), though with a notably longer $\mathrm{I}^{-\cdots} \mathrm{I}_{2}$ contact than observed for I_occ1 and I_occ2. Although there are potential $I_{2}$ adsorption sites proximate to the other $\mathrm{ZnI}_{2}$ iodine atoms, I(3), I(4) and I(6), no evidence was observed for inclusion into these sites. Analysis of the structures reveals that such adsorption would be sterically hindered by the presence of framework tpt ligands and/or included nitrobenzene molecules.
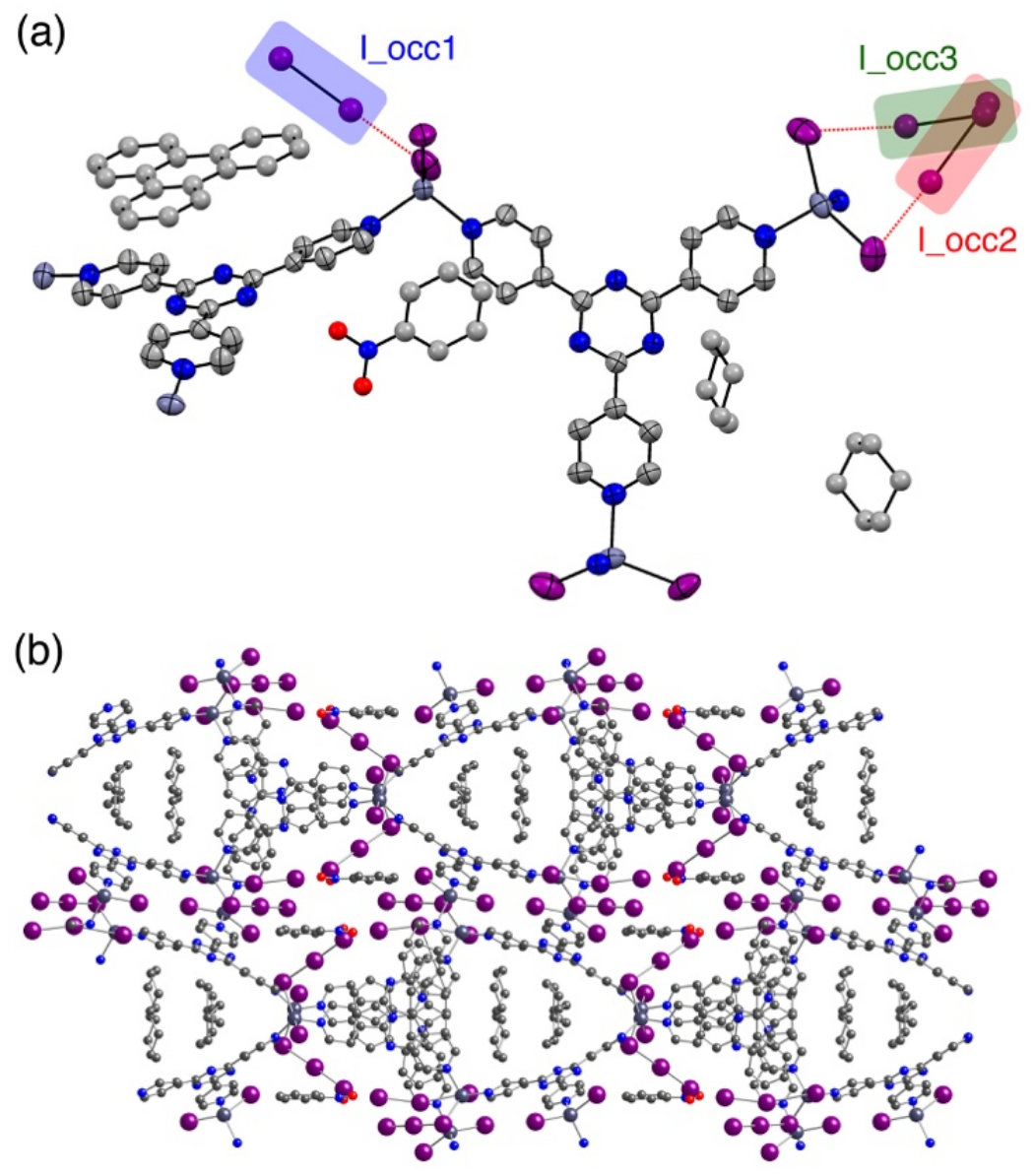

Figure 2. The structure of 1 after 90 min exposure to iodine vapor, showing (a) the asymmetric unit indicating the positions of the absorbed $\mathrm{I}_{2}$, and (b) the network structure. Hydrogen atoms have been omitted for clarity. The absorbed iodine atoms were refined with partial occupancy as described in the text. 
The framework of $\mathbf{1}$, contains two different channels (Figure 1). ${ }^{23}$ The larger channels (A) are approximately cylindrical and surrounded by hydrogen atoms of the stacked tpt and triphenylene units, while the narrower channels $(\mathbf{B})$ have three walls and are approximately trigonal prismatic. In channel A the nitrobenzene and cyclohexane guests are severely disordered while channel $\mathbf{B}$ is filled with more ordered cyclohexane molecules. All three sites for iodine inclusion are located in channel A (Figure 2b).

Further information on the iodine absorption process can be gained by monitoring the rate at which each site in the structure absorbs $\mathrm{I}_{2}$ molecules. An indication of this is given by the refined site occupancies of the I atoms at the various positions as measured in the six sequential data sets recorded over $90 \mathrm{~min}$. These results are shown in Figure 3. This shows a significant level of $\mathrm{I}_{2}$ absorption at $\mathrm{t}=0$ (the start time for the first data collection), which results from the unavoidable, approximately 5 minute time delay between sealing the crystal of $\mathbf{1}$ and iodine in the capillary before mounting it on the diffractometer. Therefore, all three of the located iodine sites start with an occupancy level of 4-7\%. All these levels rise with time with the biggest increase occurring between 6 and $45 \mathrm{~min}$. After this, the site occupancies of I_occ1 and I_occ3 continue to rise at a slower rate but in parallel. The site occupancy for I_occ2 rises slightly but levels out at $7 \%$ by $\mathrm{t}=$ 90 min. There is competition between sites I_occ2 and I_occ3 as they reside in the same region of the lattice, so full occupancy of both is not possible for steric reasons and their behavior suggests that I_occ3 takes precedence. The overall uptake of $\mathrm{I}_{2}$ observed in the dynamic crystallography experiment is 0.43 equivalents per formula unit, which corresponds to $6.0 \mathrm{wt} \%$. 


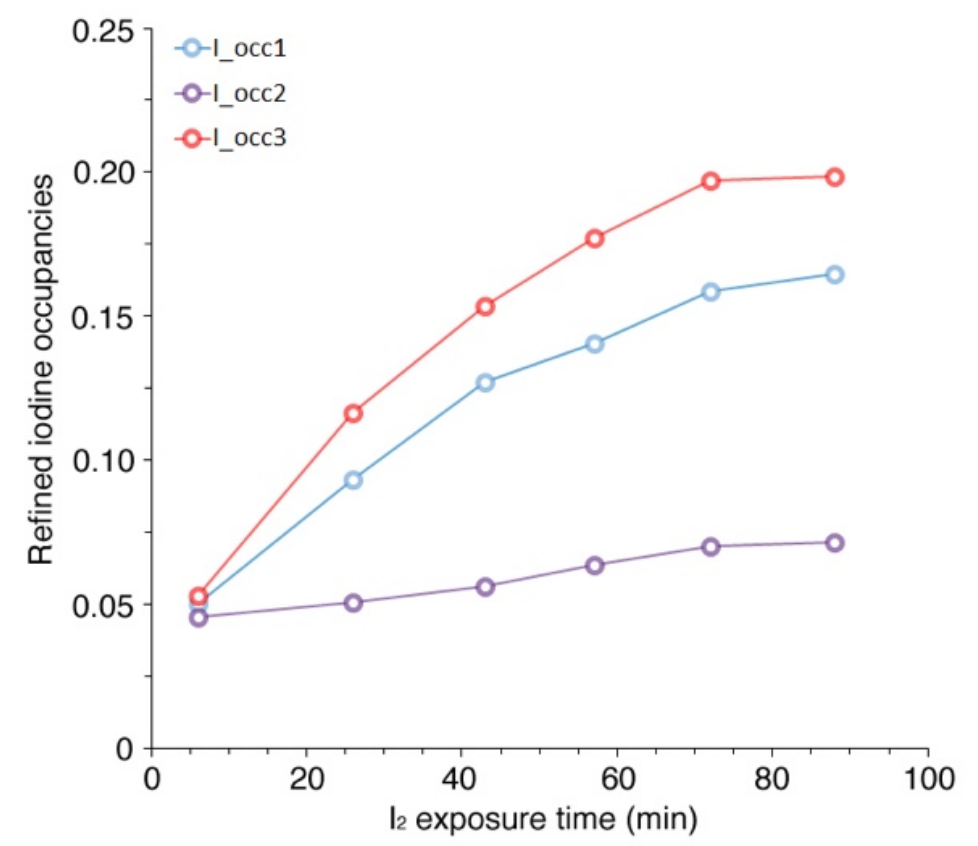

Figure 3. The modelled iodine occupancies, as percentages, for the three sites obtained from refinements of the 6 sequential data sets recorded as the single crystal of $\mathbf{1}$ absorbed iodine vapor over a 90-minute period.

In a subsequent set of experiments, a fresh crystal of $\mathbf{1}$ and an iodine crystal were mounted as before, and the data collections were repeated at $280 \mathrm{~K}$. The results were generally similar to those at $290 \mathrm{~K}$ and are presented in the supporting information (page S11). The main difference was that the rate of absorption for all three sites was notably slower at $280 \mathrm{~K}$, reaching occupancies of $9 \%$ for I_occ1, 3\% for I_occ2 and 9\% for I_occ3 after 185 minutes.

While it is known that the absorption of $\mathrm{I}_{2}$ into a porous material can instigate chemical reactions,${ }^{24}$ this is only the second time to our knowledge that chemisorption of gaseous $I_{2}$ to form coordinated $\mathrm{I}_{3}{ }^{-}$has been visualized and monitored within a porous solid-state framework. Very recently, Woo, Murugesu and co-workers ${ }^{26}$ reported the uptake of iodine into $\left[\left(\mathrm{ZnI}_{2}\right)_{3}(\operatorname{tpt})_{2}\right]$ in the absence of the triphenylene guests. They observed initial incorporation of $I_{2}$ at sites bridging 
between two coordinated iodides, giving rise to $\mathrm{I}_{4}{ }^{2-}$ ions. As greater quantities of iodine were absorbed, these $\mathrm{I}_{4}{ }^{2-}$ bridges were replaced by terminal $\mathrm{I}_{3}{ }^{-}$ions, similar to those observed for $\mathbf{1}$, and this change in coordination mode allows for greater capacity. The overall uptake of $I_{2}$ observed crystallographically in $\left[\left(\mathrm{ZnI}_{2}\right)_{3}(\mathrm{tpt})_{2}\right]$ is considerably higher than in $\mathbf{1}$, consistent with the larger pores present. The non-observation of $\mathrm{I}_{4}{ }^{2-}$ ions in $\mathbf{1}$ following exposure to $\mathrm{I}_{2}$ is likely to relate to the relative positions and orientations of the $\mathrm{ZnI}_{2}$ units in the structure. In $\mathrm{I}_{2}$-loaded $\left[(\mathrm{ZnI})_{3}(\mathrm{tpt})_{2}\right]$, the distance between the zinc-bound iodine atoms that are bridged by $\mathrm{I}_{2}$ to form $\mathrm{I}_{4}{ }^{2-}$ is $9.44 \AA$. Inspection of the structure of 1 reveals that there are no I $\cdots$ I distances between 9 and $10 \AA$ in which the orientation of the $\mathrm{ZnI}_{2}$ units could facilitate $\mathrm{I}_{2}$ bridges. Similar $\mathrm{I}_{4}{ }^{2-}$ ions were observed by Liao, Zheng and co-workers in a MOF containing $\mathrm{Cu}_{4} \mathrm{I}_{4}$ nodes and isonicotinate ions, though no evidence of $\mathrm{I}_{3}{ }^{-}$ions was reported in this case. ${ }^{30}$

While the interactions between $\left[\left(\mathrm{ZnI}_{2}\right)_{3}(\mathrm{tpt})_{2}\right]$ and $\mathbf{1}$ with iodine are the only examples to date of absorption of iodine with concurrent conversion to $\mathrm{I}_{3}^{-}$, previous papers have reported the direct uptake of triiodide from solution into a framework, ${ }^{31-32}$ solvent triggered formation of triiodide from iodine within a framework, ${ }^{33}$ and non-innocent redox processes triggered by iodine in a $\mathrm{Fe}^{2+}$ framework. ${ }^{34}$ A key advantage of the interaction described in this work is that the solution phase is by-passed in favor of harnessing reactivity at the gas/solid interface, which is desirable for materials and applications that target radioactive iodine vapor absorption.

Generally, the rate of iodine uptake for powdered $\mathbf{1}$ is slower than that in the single-crystal experiments. The dominant factor appears to be the accessibility of the material to iodine vapor. For the single-crystal experiment the entire surface of the crystal was exposed to iodine vapor using MiTeGen MicroGripper ${ }^{\mathrm{TM}}$ crystallographic loops when mounting. In contrast, only the crystallites located at the surface of the bulk powder of $\mathbf{1}$ were observed to darken quickly upon 
exposure to iodine, signaling rapid uptake. Crystallites located beneath this surface layer were largely insulated from the iodine vapor. Upon each sampling, the bulk powder was homogenized with stirring, however this insulating behavior persisted throughout the experiment.

Despite the slower kinetics, powdered $\mathbf{1}$ has a substantially higher uptake of $I_{2}$ than observed in the single crystal X-ray experiments prior to loss of single crystallinity. A powder sample of $\mathbf{1}$ was exposed to the normal vapor pressure of solid iodine at $23^{\circ} \mathrm{C}\left(3.43 \times 10^{-3} \mathrm{~atm}\right)^{35}$ and the uptake of iodine monitored by thermogravimetric analysis hourly for 7 hours (Figure 4). To identify the volatile components, continuous sampling by mass spectrometry was performed during this experiment (see ESI). Prior to iodine exposure $(t=0 \mathrm{~h})$, a mass loss of $7.8 \%$ was recorded on heating to $200{ }^{\circ} \mathrm{C}$. This corresponds to loss of included nitrobenzene and cyclohexane from the pores, with the mass loss suggesting a greater amount of included solvent present than observed in the single crystal X-ray structures, itself consistent with some solvent loss prior to the single crystal study, though no loss of solvent was observed during the single crystal experiments. Once iodine exposure had started, iterative sampling identified a linear increase of approximately $4 \%$ by mass of volatile components per hour. This was continued for $7 \mathrm{~h}$, after which time the volatile component of 1 by was $32.0 \%$ by mass. This corresponds to between 2.6 and 3.2 molecules of iodine per formula unit under these conditions, depending on whether the nitrobenzene and cyclohexane molecules were displaced by iodine during its uptake and prior to the TGA (i.e. $32.0 \%$ mass loss corresponds to $\mathrm{I}_{2}$ ), or were retained in the lattice and lost during the TGA along with the iodine (i.e. $32.0 \%-7.8 \%$ mass loss corresponds to $\mathrm{I}_{2}$ ). We have assumed throughout that triphenylene is not lost through either sublimation of displacement by $\mathrm{I}_{2}$. Its low volatility (m. pt. $198^{\circ} \mathrm{C}$, b. pt. $438^{\circ} \mathrm{C}$ ), coupled with its key structural role makes such loss highly unlikely, with no PXRD evidence for the structural change such displacement would lead to. 
Over the timescale of the PXRD analyses, the $\mathrm{I}_{2}$ uptake of is almost identical to that of the more porous triphenylene-free framework $\left[\left(\mathrm{ZnI}_{2}\right)_{3}(\mathrm{tpt})_{2}\right] \cdot{ }^{24}$ These bulk powder results show that $\mathbf{1}$ is amenable to both scale-up and application beyond the single-crystalline form, both of which are beneficial to device fabrication and practical applications.

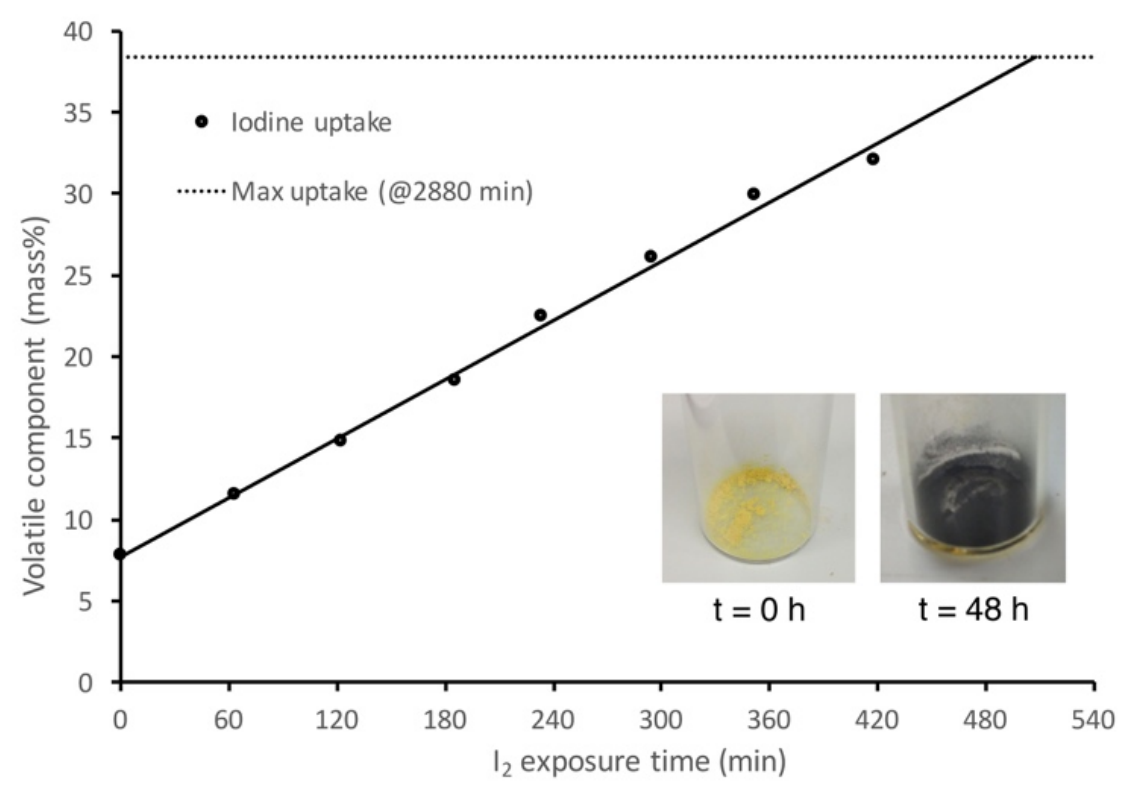

Figure 4. The increasing wt $\%$ of the volatile component within 1 upon exposure to iodine vapor as measured by thermogravimetric analysis. The solid black trend-line $\left(\mathrm{R}^{2}=0.9952\right)$ shows a linear relationship up to $\mathrm{t}=6$ hours, and possibly beyond.

\section{CONCLUSIONS}

In conclusion, we have found that $I_{2}$ is absorbed into crystals of a crystalline sponge, with an uptake of 0.43 molecules of $\mathrm{I}_{2}$ per formula unit, corresponding to $6.0 \mathrm{wt} \%$, over a 90 -minute period while retaining crystallinity. Within the crystal structures, $\mathrm{I}_{2}$ occupies three distinct positions, with 
significantly different occupancy levels, that can be related to the cavity space available within the crystal. In each case chemical reactions occurred and the $\mathrm{I}_{2}$ molecule has formed a bond to an iodine atom present in the $\mathrm{ZnI}_{2}$ unit to form a linear triiodide ligand. These interactions indicate that iodine vapour can be removed from the atmosphere and held in solid state materials through covalent bond formation.

Iodine inclusion in organic systems is often assumed to take place near to aromatic systems and accompanied by charge transfer, ${ }^{14,36}$ so direct crystallographic evidence for interaction with $\mathrm{ZnI}_{2}$ rather than the rings of the tpt ligands is significant. While single crystals of 1 only adsorb $6.0 \mathrm{wt} \%$ before loss of single crystallinity, powdered samples of $\mathbf{1}$ are capable of adsorbing considerably more $\mathrm{I}_{2}$. From the stoichiometry, it is evident that some of this additional iodine must be included into different sites from those identified in the single crystal experiments, though these X-ray analyses have clearly demonstrated the initial sites of attachment.

These results complement those for the recently published $\left[\left(\mathrm{ZnI}_{2}\right)_{3}(\mathrm{tpt})_{2}\right]$ system, ${ }^{24}$ particularly in understanding the initial iodine uptake behaviour $(\mathrm{t}<90 \mathrm{mins})$ of crystalline sponges. This work also shows that iodine can be sequestered directly as the triiodide form without first forming $\mathrm{I}_{4}^{2-}$.

\section{EXPERIMENTAL}

Triphenylene-loaded $\left[\left(\mathrm{ZnI}_{2}\right)_{3}(\mathrm{tpt})_{2}\right] \mathbf{1}$ was synthesized according to the published procedure. ${ }^{27}$ The identity of individual crystals was confirmed by single-crystal diffraction analysis and bulk purity was confirmed using powder X-ray diffraction analysis (Figure S2).

X-ray crystallography: A single crystal of $\mathbf{1}$ was mounted in a glass capillary together with several crystals of iodine; the crystals of $\mathbf{1}$ and $\mathrm{I}_{2}$ were separated by a plug of cotton wool, but iodine vapor could diffuse throughout the capillary. The glass capillary was mounted as part of a 
static gas cell, and the assembly immediately mounted on a diffractometer on beamline I19, at the Diamond Light Source. Sequential data sets were recorded approximately every 20 minutes over a 90 -minute period, at $290 \mathrm{~K}$ or $280 \mathrm{~K}$, using monochromated X-ray radiation with $\lambda=0.6889 \AA$, to follow the dynamic absorption of iodine vapor. Data were indexed and integrated in the program $x i a 2^{37}$ while structure solutions were performed by dual-space methods in $S H E L X T,{ }^{38}$ and refined by full matrix least-squares on $F^{2}$ in SHELXL. ${ }^{39}$ CCDC $1576326-1576331$ (290 K data) and 1576335-1576341 (280 K data) contain the supplementary crystallographic data for all structures in this paper. These data can be obtained free of charge from the Cambridge Crystallographic Data Centre via www.ccdc.cam.ac.uk/data request/cif.

\section{ACKNOWLEDGEMENTS}

We are grateful to the EPSRC for continued funding (EP/K004956, EP/M010481, EP/I01974X) and to Diamond Light Source Ltd for the award of beamtime (MT13015-1).

\section{REFERENCES}

(1) Riley, B. J.; Vienna, J. D.; Strachan, D. M.; McCloy, J. S.; Jerden Jr, J. L., Materials and processes for the effective capture and immobilization of radioiodine: A review. J. Nuclear Mater. 2016, 470, 307-326.

(2) Funabashi, Y.; Kitazawa, K., B. Atom. Sci. 2012, 68(2), 9-21.

(3) Verger, P.; Aurengo, A.; Geoffroy, B.; Le Guen, B., Iodine Kinetics and Effectiveness of Stable Iodine Prophylaxis After Intake of Radioactive Iodine: A Review. Thyroid 2001, 11, 353362. 
(4) Cui, Y.; Li, B.; He, H.; Zhou, W.; Chen, B.; Qian, G., Metal-Organic Frameworks as

Platforms for Functional Materials. Acc. Chem. Res. 2016, 49, 483-493.

(5) Furukawa, H.; Cordova, K. E.; O'Keeffe, M.; Yaghi, O. M., The Chemistry and Applications of Metal-Organic Frameworks. Science 2013, 341, 1230444(1)-1230444(12).

(6) Barea, E.; Montoro, C.; Navarro, J. A. R., Toxic gas removal-metal-organic frameworks for the capture and degradation of toxic gases and vapours. Chem. Soc. Rev. 2014, 43, 5419-5430. (7) Falaise, C.; Volkringer, C.; Facqueur, J.; Bousquet, T.; Gasnot, L.; Loiseau, T., Capture of iodine in highly stable metal-organic frameworks: a systematic study. Chem. Commun. 2013, 49, 10320-10323.

(8) Yao, R.-X.; Cui, X.; Jia, X.-X.; Zhang, F.-Q.; Zhang, X.-M., A Luminescent Zinc(II) MetalOrganic Framework (MOF) with Conjugated $\pi$-Electron Ligand for High Iodine Capture and Nitro-Explosive Detection. Inorg. Chem. 2016, 55, 9270-9275.

(9) Wang, Z.; Huang, Y.; Yang, J.; Li, Y.; Zhuang, Q.; Gu, J., The water-based synthesis of chemically stable Zr-based MOFs using pyridine-containing ligands and their exceptionally high adsorption capacity for iodine. Dalton Trans. 2017, 46, 7412-7420.

(10) Sava, D. F.; Rodriguez, M. A.; Chapman, K. W.; Chupas, P. J.; Greathouse, J. A.; Crozier, P. S.; Nenoff, T. M., Capture of Volatile Iodine, a Gaseous Fission Product, by Zeolitic Imidazolate Framework-8. J. Am. Chem. Soc. 2011, 133, 12398-12401.

(11) Assfour, B.; Assaad, T.; Odeh, A., In silico screening of metal organic framework for iodine capture and storage. Chem. Phys. Lett. 2014, 610-611, 45-49.

(12) Sava, D. F.; Garino, T. J.; Nenoff, T. M., Iodine Confinement into Metal-Organic Frameworks (MOFs): Low-Temperature Sintering Glasses To Form Novel Glass Composite Material (GCM) Alternative Waste Forms. Ind. Eng. Chem. Res. 2012, 51, 614-620. 
(13) Yin, Z.-J.; Xu, S.-Q.; Zhan, T.-G.; Qi, Q.-Y.; Wu, Z.-Q.; Zhao, X., Ultrahigh volatile iodine uptake by hollow microspheres formed from a heteropore covalent organic framework. Chem. Commun. 2017, 53, 7266-7269.

(14) Pei, C.; Ben, T.; Xu, S.; Qiu, S., Ultrahigh iodine adsorption in porous organic frameworks. J. Mater. Chem. A 2014, 2, 7179-7187.

(15) Zeng, M.-H.; Wang, Q.-X.; Tan, Y.-X.; Hu, S.; Zhao, H.-X.; Long, L.-S.; Kurmoo, M., Rigid Pillars and Double Walls in a Porous Metal-Organic Framework: Single-Crystal to SingleCrystal, Controlled Uptake and Release of Iodine and Electrical Conductivity. J. Am. Chem. Soc. 2010, 132, 2561-2563.

(16) Zeng, M. H.; Yin, Z.; Tan, Y. X.; Zhang, W. X.; He, Y. P.; Kurmoo, M., Nanoporous cobalt(II) MOF exhibiting four magnetic ground states and changes in gas sorption upon postsynthetic modification. J. Am. Chem. Soc. 2014, 136, 4680-4688.

(17) Inokuma, Y.; Yoshioka, S.; Ariyoshi, J.; Arai, T.; Hitora, Y.; Takada, K.; Matsunaga, S.; Rissanen, K.; Fujita, M., X-ray analysis on the nanogram to microgram scale using porous complexes. Nature 2013, 495, 461-466.

(18) Duplan, V.; Hoshino, M.; Li, W.; Honda, T.; Fujita, M., In Situ Observation of Thiol Michael Addition to a Reversible Covalent Drug in a Crystalline Sponge. Angew. Chem. Int. Ed. 2016, 55, 4919-4923.

(19) Kawahata, M.; Komagawa, S.; Ohara, K.; Fujita, M.; Yamaguchi, K., High-resolution X-ray structure of methyl salicylate, a time-honored oily medicinal drug, solved by crystalline sponge method. Tetrahedron Lett. 2016, 57, 4633-4636. 
(20) Kawamichi, T.; Kodama, T.; Kawano, M.; Fujita, M., Single-Crystalline Molecular Flasks: Chemical Transformation with Bulky Reagents in the Pores of Porous Coordination Networks. Angew. Chem. Int. Ed. 2008, 47, 8030-8032.

(21) Inokuma, Y.; Kawano, M.; Fujita, M., Crystalline molecular flasks. Nature Chem. 2011, 3, $349-358$.

(22) Biradha, K.; Fujita, M., A Springlike 3D-Coordination Network That Shrinks or Swells in a Crystal-to-Crystal Manner upon Guest Removal or Readsorption. Angew. Chem. Int. Ed. 2002, $41,3392-3395$.

(23) Ohmori, O.; Kawano, M.; Fujita, M., A Two-in-One Crystal: Uptake of Two Different Guests into Two Distinct Channels of a Biporous Coordination Network. Angew. Chem. Int. Ed. 2005, 44, 1962-1964.

(24) Knichal, J. V.; Shepherd, H. J.; Wilson, C. C.; Raithby, P. R.; Gee, W. J.; Burrows, A. D., An Iodine-Vapor-Induced Cyclization in a Crystalline Molecular Flask. Angew. Chem. Int. Ed. 2016, 55, 5943-5946.

(25) Martí-Rujas, J.; Islam, N.; Hashizume, D.; Izumi, F.; Fujita, M.; Kawano, M., Dramatic Structural Rearrangements in Porous Coordination Networks. J. Am. Chem. Soc. 2011, 133, $5853-5860$.

(26) Brunet, G.; Safin, D. A.; Aghaji, M. Z.; Robeyns, K.; Korobkov, I.; Woo, T. K.; Murugesu, M., Stepwise crystallographic visualization of dynamic guest binding in a nanoporous framework. Chem. Sci. 2017, 8, 3171-3177.

(27) Ohmori, O.; Kawano, M.; Fujita, M., Construction of biporous coordination networks via $\pi-$ $\pi$ interaction. CrystEngComm 2005, 4, 500-505. 
(28) Krap, C. P.; Newby, R.; Dhakshinamoorthy, A.; García, H.; Cebula, I.; Easun, T. L.; Savage, M.; Eyley, J. E.; Gao, S.; Blake, A. J.; Lewis, W.; Beton, P. H.; Warren, M. R.; Allan, D. R.; Frogley, M. D.; Tang, C. C.; Cinque, G.; Yang, S.; Schröder, M., Enhancement of $\mathrm{CO}_{2}$ Adsorption and Catalytic Properties by Fe-Doping of $\left[\mathrm{Ga}_{2}(\mathrm{OH})_{2}(\mathrm{~L})\right]\left(\mathrm{H}_{4} \mathrm{~L}=\right.$ Biphenyl-3,3',5,5'tetracarboxylic Acid), MFM-300(Ga2). Inorg. Chem. 2016, 55, 1076-1088.

(29) Spek, A. L., PLATON SQUEEZE: a tool for the calculation of the disordered solvent contribution to the calculated structure factors. Acta Crystallogr. Sect. C 2015, 71, 9-18. (30) Hu, Y.-Q.; Li, M.-Q.; Wang, Y.; Zhang, T.; Liao, P.-Q.; Zheng, Z.; Chen, X.-M.; Zheng, Y.Z., Direct Observation of Confined $\mathrm{I}^{-} \cdots \mathrm{I}_{2} \cdots \mathrm{I}^{-}$Interactions in a Metal-Organic Framework: Iodine Capture and Sensing. Chem. Eur. J. 2017, 23, 8409-8413.

(31) Yuan, S.; Deng, Y.-K.; Sun, D., Unprecedented Second-Timescale Blue/Green Emissions and Iodine-Uptake-Induced Single-Crystal-to-Single-Crystal Transformation in $\mathrm{Zn}{ }^{\mathrm{II}} / \mathrm{Cd}^{\mathrm{II}}$ MetalOrganic Frameworks. Chem. Eur. J. 2014, 20, 10093-10098.

(32) Gee, W. J.; Batten, S. R., Influencing the Stability of Diaminomethane-Containing Azacrown Ether Ligands in the Presence of Transition-Metal Ions. Eur. J. Inorg. Chem. 2013, $2013,3240-3248$.

(33) Choi, H. J.; Suh, M. P., Dynamic and Redox Active Pillared Bilayer Open Framework: Single-Crystal-to-Single-Crystal Transformations upon Guest Removal, Guest Exchange, and Framework Oxidation. J. Am. Chem. Soc. 2004, 126, 15844-15851.

(34) Horike, S.; Sugimoto, M.; Kongpatpanich, K.; Hijikata, Y.; Inukai, M.; Umeyama, D.; Kitao, S.; Seto, M.; Kitagawa, S., Fe ${ }^{2+}$-based layered porous coordination polymers and soft encapsulation of guests via redox activity. J. Mater. Chem. A 2013, 1, 3675-3679. 
(35) Gillespie, L. J.; Fraser, L. H. D., The Normal Vapor Pressure of Crystalline Iodine. J. Am. Chem. Soc. 1936, 58, 2260-2263.

(36) Wang, C.; Wang, Y.; Ge, R.; Song, X.; Xing, X.; Jiang, Q.; Lu, H.; Hao, C.; Guo, X.; Gao, Y.; Jiang, D., A 3D Covalent Organic Framework with Exceptionally High Iodine Capture Capability. Chem. Eur. J. 2018, 24, 585-589.

(37) Winter, G., xia2: an expert system for macromolecular crystallography data reduction. $J$. Appl. Crystallogr. 2010, 43, 186-190.

(38) Sheldrick, G. M., SHELXT - Integrated space-group and crystal- structure determination. Acta Crystallogr. Sect. A 2015, 71, 3-8.

(39) Sheldrick, G. M., Crystal structure refinement with SHELXL. Acta Crystallogr. Sect. C 2015, 71, 3-8.

\section{ASSOCIATED CONTENT}

Supporting information. Details of the crystallographic characterizations and thermogravimetric analyses. CCDC 1576326-1576331, 1576335-1576341.

\section{AUTHOR INFORMATION}

\section{Corresponding Author}

Correspondence to Professor Paul Raithby or Professor Andrew Burrows, Department of Chemistry, University of Bath, Claverton Down, Bath BA2 7AY, E-mail: p.r.raithby@bath.ac.uk, a.d.burrows@bath.ac.uk. 


\section{Author Contributions}

The manuscript was written through contributions of all authors. All authors have given approval to the final version of the manuscript. 
SYNOPSIS: Dynamic X-ray crystallographic analysis of iodine uptake into a crystalline sponge reveals three sites of adsorption, all involving interactions with $\mathrm{ZnI}_{2}$ nodes to form coordinated triiodide.

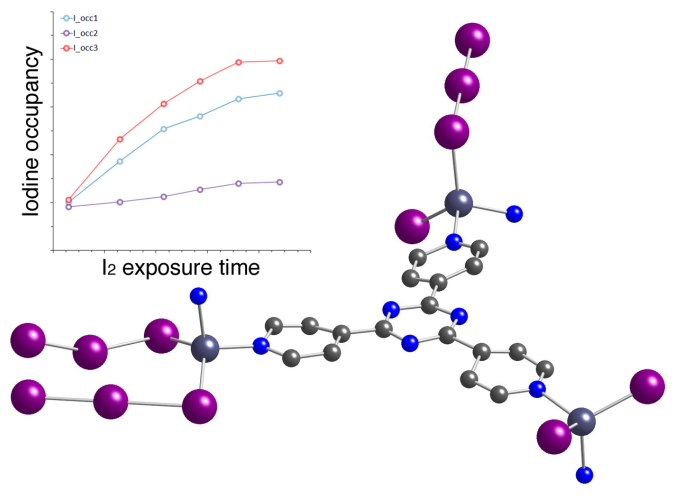

